\title{
Review of Treatment of Disruptive Mood Dysregulation Disorder
}

\author{
Cheng Huang ${ }^{1, *}$
}

\author{
${ }^{I}$ San Francisco State University, California, U.S.A. \\ *Corresponding author.Email: chuang21@mail.sfsu.edu
}

\begin{abstract}
Compared with the diagnostic criteria of Disruptive Mood Dysregulation Disorder (DMDD) and research on comorbidities, research on the treatment of DMDD is scarce. Since it was defined in 2012, children have been diagnosed with DMDD every year. They lose their temper frequently and severely and impair their daily lives. This article aims to review and summarize the relevant information of DMDD and focuses on treatment methods. The review includes drug treatment and psychotherapy. Drug treatment is divided into antidepressants, mental stabilizers, antipsychotics, and some other drugs. Although there are many treatments for the core symptom of DMDD, which is severe irritability, research is limited by insufficient samples due to low prevalence. Nevertheless, clinicians, psychologists, and scholars should continue to pay attention to the treatment of DMDD.
\end{abstract}

\section{Keywords: Disruptive Mood Dysregulation Disorder, Treatment, Irritability, Children}

\section{INTRODUCTION}

Disruptive Mood Dysregulation Disorder (DMDD) first appeared in DSM-5 as a mood disorder. The core feature of destructive mood disorders is severe and persistent irritability. And irritability is the main reason children's parents seek medical advice [1]. The patients lose their temper very easily, and this kind of situation is not proportional to the environmental stimuli received [2]. According to DSM-5, this situation generally occurs three times a week and lasts for at least one year. In addition, the symptoms must appear before the age of 10 , and the diagnosis must be made between the ages of 6 and 18. However, DMDD can share some symptoms with some diseases such as Attention Deficit and Hyperactivity Disorder (ADHD), Oppositional Defiant Disorder (ODD), Bipolar Disorder (BP), etc., which makes it very challenging to provide a clear diagnosis for a specific patient [3]. At present, the effective treatment for DMDD has not been determined, but scholars and clinicians are exploring the treatment in many aspects. Furthermore, the prevalence of DMDD is very low among adolescents in the United States [4].

According to the Global Burden of Disease Study published by The Lancet in 2013, the burden of common mental disorders, such as depression and anxiety, increases during childhood (1-10 years) and peaks during adolescence and early adulthood [5]. This means that diagnosing mental disorders in children and adolescents has always been controversial [6]. At the same time, the diagnosis rate of $\mathrm{BP}$ among children and adolescents increased significantly from 1996 to 2004 [7]. Thus, people began to worry about the diagnostic validity of the broad phenotype of bipolar disorder in children [8]. Also, some children with severe nonepisodic irritability do not suffer from bipolar disorder. This means they cannot be diagnosed with bipolar disorder and get the necessary treatment [9]. For the above reasons, "severe mood dysregulation" (SMD) was proposed by The National Institute of Mental Health (NIMH) to evaluate children who are repeatedly angry and irritable.

The main problem addressed in early SMD research is to identify children who also have irritable characteristics but do not have the clear manic phase of bipolar disorder [9]. Reviewing and based on the research on SMD, the editors of DSM- 5 created a new diagnostic category DMDD [8]. However, some of the characteristics of DMDD are different from SMD. For example, DMDD does not include the criteria for excessive activation seen in SMD, such as confused thinking, intrusiveness, insomnia, and distraction [9]. In addition, the age of onset of symptoms of DMDD is before 10 years old, while the age of onset of SMD is earlier than 12 years old [2]. 
Since DMDD first appeared in DSM-5 published in 2012, the current prevalence rate in the community is not yet clear. In a structured interview with 3258 children in 3 communities in North Carolina, the prevalence of DMDD ranged from $0.8 \%$ to $3.3 \%$, and preschool children had the highest prevalence [10]. In addition, in a population-based self-reporting study, 2413 subjects between the ages of 18-94 submitted their reports, and the results showed that $12(0.50 \%)$ subjects met in adulthood. According to the diagnostic criteria of DMDD, $19(0.79 \%)$ reported showing symptoms of DMDD during primary school age [11]. However, patients with DMDD are more common in psychiatric clinics. Twenty-two percent of children referred to an outpatient clinic due to mood disorders were diagnosed with DMDD [12]. Moreover, many sick children with DMDD have comorbidities. According to a survey, $26 \%$ of 706 children referred for bipolar disorder meet the diagnostic criteria for DMDD [13]. According to a survey of 597 adolescents aged 6-18 from community mental health centers, about $31 \%$ of adolescents meet the diagnostic criteria for DMDD [14]. In summary, although many scholars and clinicians have tried to investigate the prevalence of DMDD, the academic community cannot draw a unified conclusion due to the lack of samples.

As mentioned above, DMDD is an emerging disease. Academics and clinicians lack effective treatments for DMDD and its core symptoms. Therefore, the purpose of this article includes a review of related therapies. Different researchers have used different methods to solve related symptoms, including drug therapy and psychotherapy. Additionally, further contributions and possible improvements were discussed.

\section{METHODOLOGY}

The studies related to the treatment of DMDD were collected and analyzed. However, due to its novelty, the academic community does not have sufficient data to support it. And DMDD previously appeared in the literature under the alias of Severe Mood Disorder (SMD). At present, the symptoms of DMDD, severe and chronic irritability, and aggressive behavior are currently clinically used as the main treatment targets. Therefore, the search scope to all aggressive and irritable mood disorders was expanded. Any original research, case report, case series, meta-analysis, and literature review are included in the search criteria.

This study retrieved related articles from PubMed, SpringerLink, ScienceDirect, NCBI, The American Journal of Psychiatry, and EBSCO. Use keywords "disruptive" AND "mood" AND "dysregulation" AND "disorder" OR "Treatment" AND "DMDD" OR "Drug" AND "mood" AND "disorder" OR "Treatment" AND "SMD" OR "Treatment" AND "BP" OR "Treatment" AND "ADHD" OR "Antidepressant" OR "Mental"
AND "Stabilizer" OR "temper" AND "outburst" OR "aggressive" AND "antipsychotics" OR "aggressive" AND "psychotherapy" OR "aggressive" AND "CBT "

From the remaining records, the following eligibility criteria were used to screen and select suitable references based on the purposes of this review:

(1) Articles are freely accessible, peer-viewed, fulltext, and published in English,

(2) The release date cannot be earlier than 1995 ,

(3) The subject of investigation must be human,

(4) A book or a book chapter is excluded,

(5) The research focus is best to focus on children and adolescents,

After screening, 16 articles were included in this review.

\section{RESULTS}

Although DSM-5 adds a series of diagnostic criteria for DMDD, prevalence, comorbidity information, it does not include treatment. At present, the experience and evidence for effective treatment of DMDD are limited. But many clinicians and psychotherapists have tried different treatments, including medication and psychotherapy

\subsection{Drug Treatment}

So far, no drug has been approved by FDA to treat DMDD. Because there are no treatment standards, pharmaceutical therapy focuses on DMDD's primary symptoms, such as severe chronic irritation, temper outbursts, and stable comorbidities, such as ADHD. Many clinical investigations on the treatment of children's aggressivity or chronic irritability symptoms, on the other hand, show that there is a wide variety of DMDD pharmacological therapy options [6]. Currently, clinicians' drugs for DMDD patients include antidepressants, stimulants, anxiolytics, mood stabilizers, and antipsychotics.

\subsubsection{Antidepressants}

In fact, before DSM-5, because people did not know whether SMD was a phenotype of pediatric bipolar disorder. The use of antidepressants in DMDD patients was considered a risk because antidepressants could exacerbate irritability and promote mania in DMDD patients [15]. Evidence of a link between DMDD, unipolar depression, and anxiety disorders has moved current treatment patterns to the antidepressant, namely selective serotonin reuptake inhibitors (SSRIs). At present, there is already evidence from admitted adult samples that SSRIs have a significant effect on some mental illnesses. Although the following experiment 
does not target DMDD patients, they have similar symptoms, severe irritability, and may be accompanied by aggressive behavior.

Anger attacks in patients with depression are accompanied by aggressive behavior, and the incidence of anger attacks in patients with depression is about $30 \%$ to $40 \%$ [16]. However, when these patients received SSRIs treatment, such as fluoxetine, sertraline, or imipramine, $53 \%$ to $71 \%$ of seizures disappeared.

In addition, Intermittent Explosive Disorder (IED) exhibits similar symptoms to DMDD: severe tantrums. But the duration of the two is different [2]. At present, there is evidence that fluoxetine, a type of SSRIs, has a significant anti-attack effect on IED patients. A doubleblind, randomized, placebo-controlled trial was conducted in individuals with IED. $46 \%$ of fluoxetinetreated subjects had complete or partial relief of impulsive aggressive behavior [17].

In the treatment of severe mood dysregulation (SMD) patients, SSRIs have also shown positive effects. Citalopram (CTP), a type of SSRIs, may be effective as an adjuvant drug for treating chronic severe irritability in adolescents who are resistant to stimulant therapy alone [18]. For participants who were given CTP and methylphenidate (MPH), compared with $\mathrm{MPH}$ and placebo (PBO), the response ratio of the former was significantly higher $\quad(35 \% \quad \mathrm{CTP}+\mathrm{MPH} \quad$ vs. $6 \%$ $\mathrm{PBO}+\mathrm{MPH}$; odds ratio $=11.70,95 \% \mathrm{CI}=2.00-68.16$, $\mathrm{p}=0.006)$ [18].

As shown in Table 1, the research on antidepressants is summarized.

Table 1. Summary Review of Antidepressants

\begin{tabular}{|c|c|c|c|}
\hline $\begin{array}{l}\text { Author/s } \\
\text { and years }\end{array}$ & Disease & Participants & Medication \\
\hline $\begin{array}{l}\text { Fava and } \\
\text { Rosenbaum } \\
\text { (1999) }\end{array}$ & $\begin{array}{l}\text { Anger attacks } \\
\text { in patients } \\
\text { with } \\
\text { depression }\end{array}$ & $\begin{array}{l}45 \text { male } \\
\text { patients }\end{array}$ & $\begin{array}{l}\text { SSRIs } \\
\text { (fluoxetine, } \\
\text { sertraline, or } \\
\text { imipramine) }\end{array}$ \\
\hline $\begin{array}{l}\text { Coccaro et } \\
\text { al. (2009) }\end{array}$ & $\begin{array}{l}\text { Intermittent } \\
\text { Explosive } \\
\text { Disorder }\end{array}$ & $\begin{array}{l}100 \text { IED } \\
\text { patients }\end{array}$ & $\begin{array}{l}\text { SSRIs(fluoxetin } \\
\text { e) }\end{array}$ \\
\hline $\begin{array}{l}\text { Towbin et } \\
\text { al. (2019) }\end{array}$ & $\begin{array}{l}\text { Severe mood } \\
\text { dysregulation }\end{array}$ & 48 patients & $\begin{array}{l}\text { SSRIs(citalopra } \\
\text { m) and MPH }\end{array}$ \\
\hline
\end{tabular}

\subsubsection{Mood stabilizers}

A mood stabilizer is a psychiatric drug used to treat mood disorders, including lithium, valproate, lamotrigine, and carbamazepine. Mental stabilizers are mainly used to treat bipolar disorder and prevent the mood from turning into unipolar mania or depression. In addition, some mood stabilizers are also classified as anticonvulsants, and they are generally used to treat epilepsy.

A group of randomized, double-blind, placebocontrolled trials was implemented in SMD patients. Lithium is selected according to its potential in the treatment of irritability and aggression [19]. After the two-week placebo trial, patients who still belonged to SMD were randomized and given lithium and a placebo. However, after the 6-week double-blind experiment, the randomized patients did not show significant differences between the groups on the clinical scale and magnetic resonance spectroscopy. Therefore, although lithium is considered an effective mood stabilizer, lithium may not cause significant psychological and physical changes in SMD patients [19].

Similar to patients with DMDD, patients with conduct disorder are characterized by severe and persistent aggressive behavior. However, in a set of experiments on children and adolescents with conduct disorders, lithium has been shown to be effective. A double-blind, placebo-controlled trial was conducted using a parallel-group design in patients hospitalized with severe and chronic attacks. They were randomly assigned to the lithium or placebo group [20]. The results showed that the score of the Lithium group's public attack scale decreased significantly. However, decreased aggressiveness brought symptoms of nausea, vomiting, and frequent urination. Therefore, although lithium is used to cause adverse reactions, it is still proven to have an inhibitory effect on aggressive behavior [20].

Moreover, another mental stabilizer, Divalproex, has also been shown to be effective in adolescents with explosive tempers and emotional instability. [21]. It is worth noting that this experiment was implemented in 2000. DMDD appeared in 2012, and the predecessor of DMDD, SMD, was proposed by Dr. Leibenluft and his colleagues in 2003 [22]. However, in the experiment of Dr. Donovan and his colleagues, subjects must meet the following conditions: grumpy and have at least four attacks per month with minimal provocation, unstable mood, and chronic symptoms that last for at least one year. And these symptoms must cause damage in various situations, such as schools and homes [21]. It can be found that the subjects selected by Dr. Donovan and his colleagues are very similar to the symptoms of DMDD patients summarized in DSM-5, especially since both of them mentioned chronic irritability, the duration was at least one year, and symptoms of patients are serious on many occasions. In the experiment by Dr. Donovan and his colleagues, 20 specific children were randomized to receive 6 weeks of divalproex treatment or placebo treatment. The results showed that the 
difference between the groups was very significant. $80 \%$ of divalproex subjects responded well, but no one in the placebo group responded [21]. As shown in Table 2 , the research on Mood stabilizers is summarized.

Table 2. Summary Review of Mood stabilizers

\begin{tabular}{llll}
\hline $\begin{array}{l}\text { Author/s } \\
\text { and }\end{array}$ & Disease & Participants & Medication \\
years & & & \\
\hline Dickstein & Severe mood & 25 patients & Lithium \\
et al. & dysregulation & (aged 7-17 & \\
(2009) & (SMD) & years) & \\
& & & \\
Malone & Conduct & 40 patients & Lithium \\
et al. & disorder & (median age & \\
(2000) & & 12.5 years) & \\
& & 20 patients & Divalproex \\
Donovan & Youth with & (ages 10-18) & \\
et al. & explosive & & \\
(2000) & temper and & & \\
& mood lability & & \\
\hline
\end{tabular}

\subsubsection{Antipsychotics}

Antipsychotics are mainly used to treat a series of mental disorders, including schizoaffective disorder, delusional disorder, and bipolar disorder [23]. Antipsychotics are divided into typical antipsychotics and atypical antipsychotics. Typical antipsychotics, also known as first-generation antipsychotics, were introduced in 1950; clozapine, the first atypical antipsychotic, that is, the second-generation antipsychotic, was marketed in 1970 [24].

Despite the different times to market of the two types of drugs, And the academic circles are controversial about their effects [25]. In a meta-analysis [26], Leucht and colleagues examined 150 double-blind studies. The study involved 9 atypical antipsychotics. However, the results showed that the overall symptom effects of the five atypical antipsychotics were not significantly different from those of typical antipsychotics, and the other four were more effective than the typical antipsychotic [26].

\subsubsection{Typical antipsychotics}

Typical antipsychotics were used as one of the drugs to treat aggressive behavior before 1970. Haloperidol is one of the core therapeutic drugs [27]. According to a randomized controlled trial by Calver and colleagues, $92 \%$ of 220 patients with aggressive behavior were sedated within 120 minutes after being given droperidol or haloperidol [28]. In a randomized controlled trial using haloperidol and lithium carbonate on aggressive children hospitalized with conduct disorders. Both results are significantly different from the placebo group, but haloperidol is more likely to cause adverse reactions [29].

\subsubsection{Atypical antipsychotic}

Although atypical antipsychotics were first used for adult schizophrenia and bipolar disorder, they have also shown effectiveness in controlling aggressive behavior [30]. The FDA approves risperidone to treat irritability associated with autism in children and adolescents (including aggressiveness, tantrums, self-injurious behavior, and rapid Changing mood). And risperidone has been extensively studied. At present, risperidone has been proven to be effective for Autism [31], ODD [32], ADHD [33] patients. One hundred and one children with autism were randomized to receive risperidone or a placebo for eight weeks. The results showed that the positive reaction rate of the risperidone group was $69 \%$, while the positive reaction rate of the placebo group was only $12 \%$ [31]. One hundred and sixty-three boys diagnosed with conduct disorder or oppositional defiant disorder underwent a six-week randomized, doubleblind, placebo-controlled trial. When the researchers gave patients risperidone oral solution for six weeks, the boys' aggressiveness dropped by $56.4 \%$, more than twice that of placebo-treated subjects [32]. One hundred and fifty-five children with ADHD were grouped according to random drug treatment (risperidone or placebo). After six weeks, compared with placebo, patients treated with risperidone had significantly lower destructive behaviors clinically and statistically [33]. As shown in Table 3, the research on Antipsychotics is summarized.

Table 3. Summary Review of Antipsychotics

\begin{tabular}{llll}
\hline $\begin{array}{l}\text { Author/s } \\
\text { and years }\end{array}$ & Disease & Participants & Medication \\
\hline $\begin{array}{lll}\text { Calver et } \\
\text { al. (2015) }\end{array}$ & $\begin{array}{l}\text { Aggressive } \\
\text { behaviour } \\
\text { in acute }\end{array}$ & & \\
& $\begin{array}{l}\text { mental } \\
\text { health }\end{array}$ & Droperidol \\
& & Haloperidol \\
Anderson & Conduct & 45 children & Haloperidol \\
et al. & disorder & & and Lithium \\
(1989) & & & carbonate \\
McCracke & Autism & 101 children & Risperidone \\
n et al. & & &
\end{tabular}


(2002)

\begin{tabular}{|c|c|c|}
\hline LeBlanc et & ODD and & 163 boys \\
\hline al. (2005) & $\begin{array}{l}\text { Conduct } \\
\text { disorder }\end{array}$ & \\
\hline
\end{tabular}

Aman et $\quad$ ADHD 155 children Risperidone al. (2004)

\subsubsection{Other agents}

According to a clinical trial, U. Jain randomly divided some children (6-9 years old) into $\mathrm{A}$ and $\mathrm{B}$ groups. Group A $(n=12)$ was given a certain dose of guanfacine (GUA). Group B ( $\mathrm{n}=13)$ was not given medication support [34]. The results showed that the number of anger episodes in group A improved significantly, but the intensity did not improve significantly $(P<0.05)$. But at the same time, the performance of Group B has also changed [34]. This shows that the experimental results have limitations. GUA will be a possible therapy for DMDD in the future.

Amantadine has been shown to have an inhibitory effect on severe aggressiveness and mood disorders in patients with DMDD [35]. Dr. Timothy Rice and his colleagues received a 12-year-old hospitalized girl with a diagnosis of DMDD. The girl's parents and immediate family members have a history of mental illness, and she has experienced a series of social events such as bullying and the absence of her father [35]. After 24 days of medication, including Amantadine, the girl was in stable condition and was discharged from the hospital [35]. However, since Dr. Timothy Rice and his colleagues only used Amantadine on one child, the effectiveness of Amantadine lacked substantial sample support [35].

\subsection{Psychotherapy}

For DMDD patients, in addition to medication, psychotherapy is also essential, such as behavioral therapy and parent training intervention [36]. Among behavioral therapy, cognitive behavioral therapy (CBT) is effective for patients with DMDD. A boy who met the diagnostic criteria for DMDD received 12 CBT treatments, and his clinical severity was reduced [37]. And there are currently many researchers and scholars trying and developing CBT projects in different directions. CBT for aggressive behavior can already be used as a viable treatment for DMDD patients. A girl who exhibited 3 to 4 tantrums and 2 to 3 aggressive behaviors per week received 17 CBT sessions, and her symptoms were significantly reduced [38]. In addition, some researchers provided data on a novel exposurebased cognitive behavioral therapy for severe irritability that also proved its effectiveness [40]. Furthermore, Dialectical behavior therapy (DBT) combines CBT, mindfulness, and systemic characteristics [39]. Dialectical behavior therapy adapted for pre-adolescent children (DBT-C) has also been shown to have a high response rate in the face of emotional disorders and irritable children. Forty-three children with DMDD from 7 to 12 years old were randomly divided into the DBT-C treatment group or the conventional treatment group. The positive response rate of DBT-C was $90.4 \%$, while the positive response rate of conventional treatment was $45.5 \%$ [40].

\section{DISCUSSION}

This review analyzes articles related to Disruptive Mood Dysregulation Disorder and focuses on treatment, including drug therapy and psychotherapy. The review found that there is currently insufficient research on DMDD in academia. However, due to the similar core symptom, severe irritability, many treatments for this can also be used for DMDD. But many of these articles were published before DMDD was defined. Therefore, this article cannot determine that these therapies are definitely effective for patients with DMDD. But now, some scholars are trying the effectiveness of these therapies. Furthermore, comorbidities also need to be noted. Many patients with DMDD have symptoms compatible with other opposing defiant disorders, such as ADHD and ODD. Generally speaking, patients with these diseases show destructive behaviors. In addition, most psychotherapy subjects are individual cases, which means that the effectiveness of the corresponding therapy is difficult to prove fully. Therefore, this article does not describe in detail the psychotherapy for DMDD. But we cannot deny the importance of psychotherapy. For example, CBT has shown positive effects in a variety of oppositional defiant disorders. In future research, psychologists should pay attention to these aspects.

\section{CONCLUSION}

This review analyzes the treatment of DMDD, including medication and psychotherapy. Many therapies have shown their strength in the face of patients with DMDD or those who appear to be severely irritable. Although scholars and clinicians are trying different therapies to target DMDD and its core symptoms, the effectiveness of the therapy is controversial due to the low prevalence and low attention. Therefore, this article is meant for doctors in outpatient clinics of psychiatric hospitals, community mental health centers employees, and scholars who pay attention to this field. Like most mental illnesses, it is difficult for us to find specific treatments for DMDD, but this does not mean that we give up on research. 


\section{REFERENCES}

[1] Yeh, May, \& Weisz, John R. (2001). Why Are We Here at the Clinic? Parent-Child (Dis)Agreement on Referral Problems at Outpatient Treatment Entry. Journal of Consulting and Clinical Psychology, 69(6), 1018-1025. https://doi.org/10.1037/0022-006X.69.6.1018.

[2] American Psychiatric Association. (2013). Diagnostic and statistical manual of mental disorders: DSM-5. (5th ed.). American Psychiatric Association.

[3] Parens, Erik, \& Johnston, Josephine. (2010). Controversies concerning the diagnosis and treatment of bipolar disorder in children. Child and Adolescent Psychiatry and Mental Health, 4(1), 99. https://doi.org/10.1186/1753-2000-4-9.

[4] Althoff, Robert R, Crehan, Eileen T, He, Jian-Ping, Burstein, Marcy, Hudziak, James J, \& Merikangas, Kathleen R. (2016). Disruptive Mood Dysregulation Disorder at Ages 13-18: Results from the National Comorbidity SurveyAdolescent Supplement. Journal of Child and Adolescent Psychopharmacology, 26(2), 17-113. https://doi.org/10.1089/cap.2015.0038.

[5] Whiteford, Harvey A, Prof, Degenhardt, Louisa, Prof, Rehm, Jürgen, Prof, Baxter, Amanda J, MPH, Ferrari, Alize J, BPsySc, Erskine, Holly E, BPsySc, Charlson, Fiona J, MPH, Norman, Rosana E, PhD, Flaxman, Abraham D, PhD, Johns, Nicole, BA, Burstein, Roy, BA, Murray, Christopher JL, Prof, \& Vos, Theo, Prof. (2013). Global burden of disease attributable to mental and substance use disorders: findings from the Global Burden of Disease Study 2010. The Lancet (British Edition), 382(9904), $1575-1586$. https://doi.org/10.1016/S0140-6736(13)61611-6.

[6] Chen, Jun, Wang, Zuowei, \& Fang, Yiru. (2016). The History, Diagnosis and Treatment of Disruptive Mood Dysregulation Disorder. Shanghai Jingshen Yixue, 28(5), 289-292. https://doi.org/10.11919/j.issn.1002-0829.216071.

[7] Blader, Joseph C, \& Carlson, Gabrielle A. (2007). Increased Rates of Bipolar Disorder Diagnoses Among U.S. Child, Adolescent, and Adult Inpatients, 1996-2004. Biological Psychiatry (1969), 62(2), 107-114. https://doi.org/10.1016/j.biopsych.2006.11.006.

[8] Baweja, Raman, Mayes, Susan D, Hameed, Usman, \& Waxmonsky, James G. (2016). Disruptive mood dysregulation disorder: current insights. Neuropsychiatric Disease and Treatment, 12, 2115-2124. https://doi.org/10.2147/NDT.S100312.
[9] Leibenluft, Ellen. (2011). Severe Mood Dysregulation, Irritability, and the Diagnostic Boundaries of Bipolar Disorder in Youths. The American Journal of Psychiatry, 168(2), 129-142. https://doi.org/10.1176/appi.ajp.2010.10050766.

[10] Copeland, W. E., Angold, A., Costello, E. J., \& Egger, H. (2013). Prevalence, comorbidity, and correlates of DSM-5 proposed disruptive mood dysregulation disorder. The American journal of psychiatry, 170(2), 173-179. https://doi.org/10.1176/appi.ajp.2012.12010132.

[11] Grau, K., Plener, P. L., Hohmann, S., Fegert, J. M., Brähler, E., \& Straub, J. (2018). Prevalence Rate and Course of Symptoms of Disruptive Mood Dysregulation Disorder (DMDD). Zeitschrift fur Kinder- und Jugendpsychiatrie und Psychotherapie, 46(1), 29 - 38. https://doi.org/10.1024/14224917/a000552.

[12] Benarous, X., Renaud, J., Breton, J. J., Cohen, D., Labelle, R., \& Guilé, J.-M. (2020). Are youths with disruptive mood dysregulation disorder different from youths with major depressive disorder or persistent depressive disorder? Journal of Affective Disorders, 265, 207-215. https://doi.org/10.1016/j.jad.2020.01.020.

[13] Freeman, A. J., Youngstrom, E. A., Youngstrom, J. K., \& Findling, R. L. (2016). Disruptive Mood Dysregulation Disorder in a Community Mental Health Clinic: Prevalence, Comorbidity and Correlates. Journal of Child and Adolescent Psychopharmacology, 26(2), 123-130. https://doi.org/10.1089/cap.2015.0061.

[14] Margulies, D. M., Weintraub, S., Basile, J., Grover, P. J., \& Carlson, G. A. (2012). Will disruptive mood dysregulation disorder reduce false diagnosis of bipolar disorder in children? Disruptive mood dysregulation disorder in children. Bipolar Disorders, $\quad 14(5), \quad$ 488-496. https://doi.org/10.1111/j.1399-5618.2012.01029.x.

[15] Bruno, Antonio, Celebre, Laura, Torre, Giovanna, Pandolfo, Gianluca, Mento, Carmela, Cedro, Clemente, Zoccali, Rocco A, \& Muscatello, Maria Rosaria Anna. (2019). Focus on Disruptive Mood Dysregulation Disorder: A review of the literature. Psychiatry Research, 279, 323-330. https://doi.org/10.1016/j.psychres.2019.05.043.

[16] Fava, M., \& Rosenbaum, J. F. (1999). Anger attacks in patients with depression. The Journal of clinical psychiatry, 60 Suppl 15, 21-24.

[17]Coccaro, E. F., Lee, R. J., \& Kavoussi, R. J. (2009). A double-blind, randomized, placebo-controlled trial of fluoxetine in patients with intermittent 
explosive disorder. The Journal of clinical psychiatry, 70(5), 653-662. https://doi.org/10.4088/JCP.08m04150.

[18] Towbin, K., Vidal-Ribas, P., Brotman, M. A., Pickles, A., Miller, K. V., Kaiser, A., Vitale, A. D., Engel, C., Overman, G. P., Davis, M., Lee, B., McNeil, C., Wheeler, W., Yokum, C. H., Haring, C. T., Roule, A., Wambach, C. G., Sharif-Askary, B., Pine, D. S., ... Stringaris, A. (2020). A DoubleBlind Randomized Placebo-Controlled Trial of Citalopram Adjunctive to Stimulant Medication in Youth With Chronic Severe Irritability. Journal of the American Academy of Child and Adolescent Psychiatry, 59(3), 350-361. https://doi.org/10.1016/j.jaac.2019.05.015.

[19] Dickstein, D. P., Towbin, K. E., Van Der Veen, J. W., Rich, B. A., Brotman, M. A., Knopf, L., Onelio, L., Pine, D. S., \& Leibenluft, E. (2009). Randomized double-blind placebo-controlled trial of lithium in youths with severe mood dysregulation. Journal of Child and Adolescent Psychopharmacology, 19(1), 61-73. https://doi.org/10.1089/cap.2008.044.

[20] Malone, R. P., Delaney, M. A., Luebbert, J. F., Cater, J., \& Campbell, M. (2000). A double-blind placebo-controlled study of lithium in hospitalized aggressive children and adolescents with conduct disorder. Archives of general psychiatry, 57(7), 649-654.

https://doi.org/10.1001/archpsyc.57.7.649.

[21] Donovan, S. J., Stewart, J. W., Nunes, E. V., Quitkin, F. M., Parides, M., Daniel, W., Susser, E., \& Klein, D. F. (2000). Divalproex Treatment for Youth With Explosive Temper and Mood Lability: A Double-Blind, Placebo-Controlled Crossover Design. The American Journal of Psychiatry, 157(5), 818-820. https://doi.org/10.1176/appi.ajp.157.5.818.

[22] Leibenluft, E., Charney, D. S., Towbin, K. E., Bhangoo, R. K., \& Pine, D. S. (2003). Defining Clinical Phenotypes of Juvenile Mania. The American Journal of Psychiatry, 160(3), 430-437. https://doi.org/10.1176/appi.ajp.160.3.430.

[23] Lally, J., \& MacCabe, J. H. (2015). Antipsychotic medication in schizophrenia: a review. British Medical Bulletin, 114(1), 169-179. https://doi.org/10.1093/bmb/ldv017.

[24] Shen, W. W. (1999). A history of antipsychotic drug development. Comprehensive Psychiatry, 40(6), 407-414. https://doi.org/10.1016/S0010440X(99)90082-2.
[25] Tyrer, P., \& Kendall, T. (2009). The spurious advance of antipsychotic drug therapy. The Lancet (British Edition), 373(9657), 4-5. https://doi.org/10.1016/S0140-6736(08)61765-1.

[26] Leucht, S., Corves, C., Arbter, D., Engel, R. R., Li, C., \& Davis, J. M. (2009). Second-generation versus first-generation antipsychotic drugs for schizophrenia: a meta-analysis. The Lancet (British Edition), 373(9657), 31-41. https://doi.org/10.1016/S0140-6736(08)61764-X.

[27] SCHUR, S. B., SIKICH, L., FINDLING, R. L., MALONE, R. P., CRISMON, M. L., DERIVAN, A., MACINTYRE, J. C., PAPPADOPULOS, E., GREENHILL, L., SCHOOLER, N., VAN ORDEN, K., \& JENSEN, P. S. (2003). Treatment Recommendations for the Use of Antipsychotics for Aggressive Youth (TRAAY). Part I: A Review. Journal of the American Academy of Child and Adolescent Psychiatry, 42(2), 132-144. https://doi.org/10.1097/00004583-20030200000007.

[28] Calver, L., Drinkwater, V., Gupta, R., Page, C. B., \& Isbister, G. K. (2015). Droperidol v. haloperidol for sedation of aggressive behaviour in acute mental health: Randomised controlled trial. British Journal of Psychiatry, 206(3), 223-228. https://doi.org/10.1192/bjp.bp.114.150227.

[29] Anderson, L. T., Campbell, M., Adams, P., Small, A. M., Perry, R., \& Shell, J. (1989). The effects of haloperidol on discrimination learning and behavioral symptoms in autistic children. Journal of autism and developmental disorders, 19(2), 227 239. https://doi.org/10.1007/BF02211843.

[30] Sikich, L., Hamer, R. M., Bashford, R. A., Sheitman, B. B., \& Lieberman, J. A. (2004). A pilot study of risperidone, olanzapine, and haloperidol in psychotic youth: a double-blind, randomized, 8-week trial. Neuropsychopharmacology : official publication of the American College of Neuropsychopharmacology, 29(1), 133-145. https://doi.org/10.1038/sj.npp.1300327.

[31] McCracken, J. T., McGough, J., Shah, B., Cronin, P., Hong, D., Aman, M. G., Arnold, L. E., Lindsay, R., Nash, P., Hollway, J., McDougle, C. J., Posey, D., Swiezy, N., Kohn, A., Scahill, L., Martin, A., Koenig, K., Volkmar, F., Carroll, D., Lancor, A., ... Research Units on Pediatric Psychopharmacology Autism Network (2002). Risperidone in children with autism and serious behavioral problems. The New England journal of medicine, 347(5), 314-321. https://doi.org/10.1056/NEJMoa013171. 
[32] LeBlanc, J. C., Binder, C. E., Armenteros, J. L., Aman, M. G., Wang, J. S., Hew, H., \& Kusumakar, V. (2005). Risperidone reduces aggression in boys with a disruptive behaviour disorder and below average intelligence quotient: analysis of two placebo-controlled randomized trials. International clinical psychopharmacology, 20(5), 275-283. https://doi.org/10.1097/01.yic.0000166403.03732.7 2.

[33] Aman, M. G., Binder, C., \& Turgay, A. (2004). Risperidone effects in the presence/absence of psychostimulant medicine in children with ADHD, other disruptive behavior disorders, and subaverage IQ. Journal of child and adolescent psychopharmacology, 14(2), 243-254. https://doi.org/10.1089/1044546041649020.

[34] Jain, U. (2017). The use of guanfacine (Intuniv XR) in the treatment of disruptive mood dysregulation disorder - Clinical experience from telepsychiatry. European Psychiatry, 41(S1), S442-S442. https://doi.org/10.1016/j.eurpsy.2017.01.449.

[35] Rice, Timothy, Simon, Hannah, Barcak, Danielle, Maiyuran, Harinee, Chan, Vivian, Hassan, Yonis, Tatum, Jasmine, \& Coffey, Barbara J. (2019). Amantadine for Treatment of Disruptive Mood Dysregulation Disorder Symptoms. Journal of Child and Adolescent Psychopharmacology, 29(8), 642-646. https://doi.org/10.1089/cap.2019.29172.bjc.

[36] Bruno, Antonio, Celebre, Laura, Torre, Giovanna, Pandolfo, Gianluca, Mento, Carmela, Cedro, Clemente, Zoccali, Rocco A, \& Muscatello, Maria Rosaria Anna. (2019). Focus on Disruptive Mood Dysregulation Disorder: A review of the literature. Psychiatry Research, 279, 323-330. https://doi.org/10.1016/j.psychres.2019.05.043.

[37] Linke, Julia, Kircanski, Katharina, Brooks, Julia, Perhamus, Gretchen, Gold, Andrea L, \& Brotman, Melissa A. (2020). Exposure-Based CognitiveBehavioral Therapy for Disruptive Mood Dysregulation Disorder: An Evidence-Based Case Study. Behavior Therapy, 51(2), 320-333. https://doi.org/10.1016/j.beth.2019.05.007.

[38] Tudor, Megan E, Ibrahim, Karim, Bertschinger, Emilie, Piasecka, Justyna, \& Sukhodolsky, Denis G. (2016). Cognitive-Behavioral Therapy for a 9Year-Old Girl With Disruptive Mood Dysregulation Disorder. Clinical Case Studies, 15(6), 459-475. https://doi.org/10.1177/1534650116669431.

[39] Roza, T. H., Patusco, L. M., Zimerman, A., Ballester, P., \& Passos, I. C. (2020).Precision medicine in the assessment of suicide risk. Precision Medicine for Investigators, Practitioners and Providers, 331-342. https://doi.org/10.1016/b978-0-12-8191781.00032-0.

[40] Perepletchikova, Francheska, Nathanson, Donald, Axelrod, Seth R, Merrill, Caitlin, Walker, Amy, Grossman, Meredith, Rebeta, James, Scahill, Lawrence, Kaufman, Joan, Flye, Barbara, Mauer, Elizabeth, \& Walkup, John. (2017). Randomized Clinical Trial of Dialectical Behavior Therapy for Preadolescent Children With Disruptive Mood Dysregulation Disorder: Feasibility and Outcomes. Journal of the American Academy of Child and Adolescent Psychiatry, 56(10), 832-840. https://doi.org/10.1016/j.jaac.2017.07.789. 